\title{
In situ Observations of Transformation Behavior upon Heating for a 1.5Mn-1.5Si-0.2C Steel -Comparison between Neutron Diffraction, XRD, EBSD and Dilatometry-
}

\author{
Yo TOMOTA, ${ }^{1) *}$ Nobuaki SEKIDO, ${ }^{2)}$ Stefanus HARJO, ${ }^{3)}$ Takuro KAWASAKI, ${ }^{3)}$ Wu GONG $^{4)}$ and Akira TANIYAMA ${ }^{5)}$ \\ 1) Research Center of Structure Materials, National Institute for Materials Science, 1-2-1 Sengen, Tsukuba, Ibaraki, 305-0047 \\ Japan. $\quad 2)$ Research Center of Structure Materials, National Institute for Materials Science. Now at Tohoku University, \\ 6-6-02 Aobayama, Sendai, 980-8579 Japan. $\quad 3$ 3) J-PARC Center, Japan Atomic Energy Agency, 2-4, Shirakata, Tokai, \\ Naka-gun, Ibaraki, 319-1195 Japan. $\quad 4)$ Elements Strategy Initiative for Structural Materials, Kyoto University, Yoshida- \\ honmachi, Sakyo-ku, Kyoto, 606-8501 Japan. $\quad$ 5) Advanced Technology Research Laboratories, Nippon Steel \& Sumi- \\ tomo-Metal Co., 20-1, Shintomi, Futtsu, Chiba, 293-8511 Japan.
}

(Received on May 12, 2017; accepted on July 14, 2017)

\begin{abstract}
The austenite reverse transformation behavior in a $1.5 \mathrm{Mn}-1.5 \mathrm{Si}-0.2 \mathrm{C}$ steel was in situ monitored using dilatometry, electron back scatter diffraction (EBSD), X-ray diffraction and neutron diffraction. The austenite reversion kinetics showed excellent agreements between dilatometry and neutron diffraction, whereas the austenite formation was observed to start at much higher temperature in cases of EBSD and X-ray diffraction measurements. Such discrepancy in transformation temperature is attributed to the change in chemical compositions near the surface of a specimen heated to elevated temperatures either in vacuum (EBSD) or in a helium gas atmosphere (X-ray); $\mathrm{Mn}$ and $\mathrm{C}$ concentrations were found to decrease with heating. In situ neutron diffraction enables us to investigate the changes in lattice constants of ferrite and austenite, showing not only thermal expansion but also suggesting carbon enrichment and phase stresses during the decomposition of the retained austenite and austenite reversion upon heating.
\end{abstract}

KEY WORDS: reverse transformation; austenite volume fraction; neutron diffraction; X-ray diffraction; electron back scatter diffraction; dilatometry; in situ measurement.

\section{Introduction}

The control of volume fraction, morphology, grain size and carbon concentration of the retained austenite has been a recent key technology to develop advanced steels with high strength and high ductility. Such examples include low alloyed TRIP steels, ${ }^{1-4)}$ Q\&P steels, ${ }^{5,6}$ nano-bainite steels, ${ }^{7-10)}$ medium Mn steels, ${ }^{11,12)}$ etc. Hence, the characterization of the retained austenite is very important and many studies have been performed so far. ${ }^{13-17)}$ In most of such works, a specimen was interruptedly quenched during material processing in order to freeze its microstructure at a certain elevated temperature. It is, however, difficult to freeze high temperature microstructure completely and hence not easy to track microstructural evolution continuously at the same observation position of a specimen.

Therefore, in situ observations and/or measurements of microstructural change during heat treatment have been expected to be realized by using various techniques. ${ }^{18-20)}$ In this study, dilatometry measurement, in situ electron back scatter diffraction (EBSD) measurement, in situ X-ray diffraction and in situ neutron diffraction were examined to

* Corresponding author: E-mail: TOMOTA.Yo@nims.go.jp

DOI: http://dx.doi.org/10.2355/isijinternational.ISIJINT-2017-272 monitor the decomposition behavior of the retained austenite and austenite reverse transformation during continuous heating for a low alloyed $\mathrm{Mn}-\mathrm{Si}-\mathrm{C}$ steel.

\section{Experimental Procedures}

\subsection{Materials and Microstructure Observations}

Specimens used in this study were prepared as common round robin tests for the project of New Energy and Industrial Technology Development organization (NEDO) as well as the ISIJ research project on the microstructure evaluation using compact neutron source. The details on the specimen preparation were reported elsewhere ${ }^{21)}$ and hence brief explanation is given here. The chemical compositions of the steel were $0.20 \mathrm{C}-1.50 \mathrm{Mn}-1.52 \mathrm{Si}-0.009 \mathrm{P}-0.001 \mathrm{~S}$ mass $\%$, prepared referring to Sugimoto et al.'s report. ${ }^{22)}$ Steel sheets with $1.2 \mathrm{~mm}$ in thickness, $120 \mathrm{~mm}$ in length and $100 \mathrm{~mm}$ in width were differently heat treated to prepare three different microstructures, TR1, TR2 and TR3.

$\mathrm{TR} 1: \mathrm{RT} \rightarrow\left(10^{\circ} \mathrm{C} / \mathrm{s}\right) \rightarrow 780^{\circ} \mathrm{C}, 300 \mathrm{~s} \rightarrow\left(50^{\circ} \mathrm{C} / \mathrm{s}\right) \rightarrow 400^{\circ} \mathrm{C}$, $30 \mathrm{~s} \rightarrow\left(50^{\circ} \mathrm{C} / \mathrm{s}\right) \rightarrow \mathrm{RT}$

$\mathrm{TR} 2: \mathrm{RT} \rightarrow\left(10^{\circ} \mathrm{C} / \mathrm{s}\right) \rightarrow 780^{\circ} \mathrm{C}, 300 \mathrm{~s} \rightarrow\left(50^{\circ} \mathrm{C} / \mathrm{s}\right) \rightarrow 400^{\circ} \mathrm{C}$, $300 \mathrm{~s} \rightarrow\left(50^{\circ} \mathrm{C} / \mathrm{s}\right) \rightarrow \mathrm{RT}$

TR3: $\mathrm{RT} \rightarrow\left(10^{\circ} \mathrm{C} / \mathrm{s}\right) \rightarrow 780^{\circ} \mathrm{C}, 300 \mathrm{~s} \rightarrow\left(50^{\circ} \mathrm{C} / \mathrm{s}\right) \rightarrow \mathrm{RT}$ (below $\left.50^{\circ} \mathrm{C}\right) \rightarrow\left(65^{\circ} \mathrm{C} / \mathrm{s}\right) \rightarrow 650^{\circ} \mathrm{C}, 300 \mathrm{~s} \rightarrow\left(50^{\circ} \mathrm{C} / \mathrm{s}\right) \rightarrow \mathrm{RT}$ 
Microstructures of TR1, TR2 and TR3 were observed using transmission electron microscopy (TEM), scanning electron microscopy (SEM) and EBSD, the details of which were reported elsewhere. ${ }^{21)}$

\subsection{Dilatometry Measurement}

As a conventional experimental method, dilatometry test was performed using a dilatometer (NETZSCH TD5000SA) for a specimen with $4 \mathrm{~mm}$ by $15 \mathrm{~mm}$ by $1 \mathrm{~mm}$ in an argon gas atmosphere. The specimens were heated with a heating speed of $3^{\circ} \mathrm{C} / \mathrm{min}$ from RT up to $950^{\circ} \mathrm{C}$, held there for $10 \mathrm{~min}$, and then cooled with a speed of $3^{\circ} \mathrm{C} / \mathrm{min}$ down to $400^{\circ} \mathrm{C}$.

\subsection{In situ EBSD Observations during Heating}

The experimental procedure employed here was almost identical to that in a previous work, ${ }^{19)}$ in which the austenite memory phenomenon was successfully observed, showing good coincidence with in situ neutron diffraction results. ${ }^{20)}$ A specimen with $5 \mathrm{~mm} \times 7 \mathrm{~mm} \times 0.7 \mathrm{~mm}$ was finished by polishing with emery papers and finally by electrolytic polishing. The specimen was embedded into a specially developed holder for high temperature EBSD measurement (HSEA-1000 (TSL solutions K.K.)). EBSD measurements were carried out using a scanning electron microscope of JSM-7001F with OIM7.0. A thermo-couple was welded on the specimen. The specimen was heated up to $750^{\circ} \mathrm{C}$ with a heating rate of $200^{\circ} \mathrm{C} / \mathrm{min}$ after observation at RT. Such a rapid heating was employed in order to avoid sever decarburization around $300^{\circ} \mathrm{C}$. Then, from 750 to $950^{\circ} \mathrm{C}$, a heating rate of $3^{\circ} \mathrm{C} / \mathrm{min}$ was used. Each EBSD measurement was performed for the observation area of $50 \mu \mathrm{m}$ by $50 \mu \mathrm{m}$ with a magnification of 1500 times and a scanning step size of $0.2 \mu \mathrm{m}$ was used. Then, it took approximately 2 min to finish each EBSD measurement. To realize quick data acquisition, the HIKARI detector with an accelerating current of $10 \mathrm{~mA}$ was chosen. Another approximately $1 \mathrm{~min}$ was needed for data saving and adjusting the observation at the same viewing area. As results, stepwise measurements were performed almost every $3 \mathrm{~min}$.

\subsection{In situ X-ray Diffraction during Heating}

Specimens with $10 \mathrm{~mm} \times 9 \mathrm{~mm} \times 1 \mathrm{~mm}$ were prepared from TR2 and TR3 sheets and the plane perpendicular to the normal $(\mathrm{N})$ direction was polished with emery papers and finished by buffing with alumina powder $(0.1 \mu \mathrm{m}$ in diameter). High temperature X-ray diffraction was performed in a helium gas atmosphere using a multi-purpose X-ray diffractometer made by Spectris Co., Ltd. The target and filter used were $\mathrm{Co}$ and Fe film (X-ray wavelength: 0.178919 $\mathrm{nm})$, respectively, and the accelerating voltage and current were $40 \mathrm{kV}$ and $35 \mathrm{~mA}$, respectively. The irradiation area was approximately $2.5 \mathrm{~mm}$ by $5 \mathrm{~mm}$. The scanning angle of 47 to 63 degrees was measured using one-dimensional position sensitive detector. A specimen was heated in a step by step heating manner with a heating rate of $0.25^{\circ} \mathrm{C} / \mathrm{s}$. The temperatures kept for measurement will be mentioned later and every X-ray diffraction measurement was conducted after holding for $10 \mathrm{~min}$ at each temperature.

\subsection{In situ Neutron Diffraction during Heating}

Five plates with $1.2 \mathrm{~mm}$ in thickness, $30 \mathrm{~mm}$ in length and 4-6 mm in width were stacked to be nearly cylindrical shape (shown later in Fig. 10). Such bundled specimens were set in a conventional dilatometer which was installed into an engineering neutron diffractometer, BL19, Takumi at the Materials and Life Science Experimental Facility of the Japan Proton Accelerator Research Complex (J-PARC MLF), the details of which are found in ref. 23. A slit of $5 \mathrm{~mm}$ by $5 \mathrm{~mm}$ for the incident beam and a $5 \mathrm{~mm}$ collimator for diffraction beam were used for neutron diffraction with a medium intensity mode. The specimens were set in such a way that the angle between the incident beam and the longitudinal (rolling: $\mathrm{R}$ ) direction of a specimen became 45 degrees. By orthogonally installed two detector-banks, diffraction profiles with respect to $\mathrm{R}$ and $\mathrm{N}$ directions were recorded simultaneously. Since the instruments at J-PARC MLF have employed the event-mode data acquisition system, the slicing of time can be changed freely after measurement. In the present case, the profiles obtained by every $1 \mathrm{~min}$ were used for data analysis. Specimens were heated in vacuum with a heating rate of $3^{\circ} \mathrm{C} / \mathrm{min}$ up to $950^{\circ} \mathrm{C}$. The dilatometry data were also recorded during the neutron diffraction measurement.

\section{Experimental Results and Discussion}

\subsection{Microstructures}

Microstructures before heating were reported in another paper $^{21)}$ and then briefly explained here in Fig. 1. Specimens TR1 and TR2 are composed of ferrite matrix and net-worked second phase region which consists of the retained austenite as shown in Fig. 1(b) and bainite (and/or martensite). The retained austenite was confirmed not only by EBSD and TEM in Fig. 1(c) but also X-ray and neutron diffractions. On
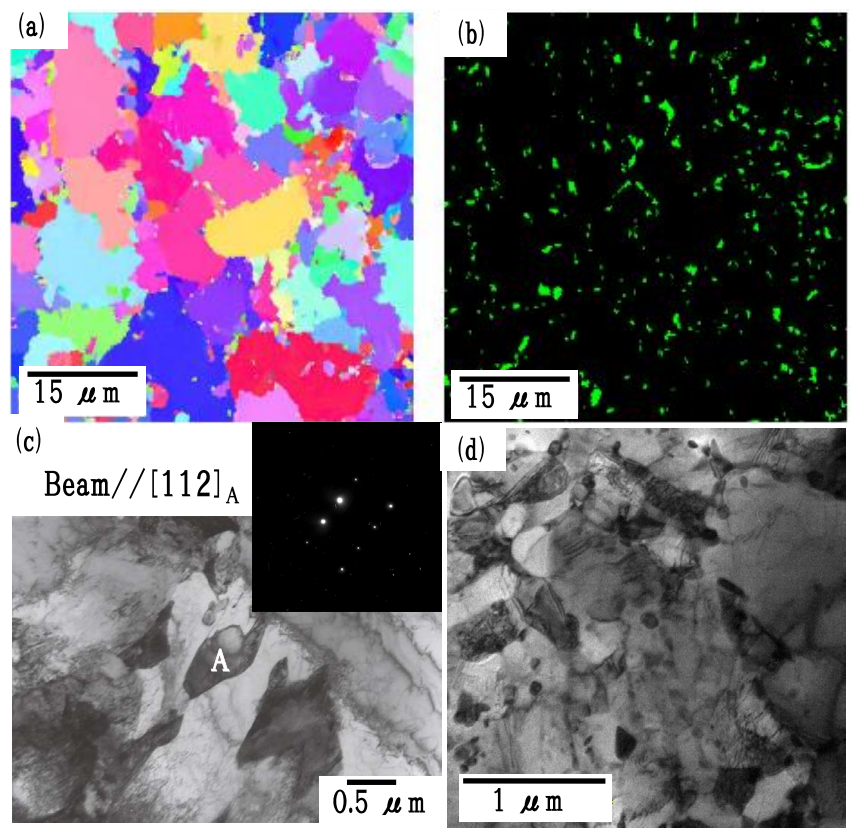

Fig. 1. Microstructures of specimens before heating: (a) IPF map obtained by SEM/EBSD of TR2, (b) phase map (green: austenite, 4-6\%) of TR2, (c) TEM microstructure of TR1 in which an austenite grain is labeled by A and (d) TEM microstructure of TR3. (Online version in color.) 
the other hand, as shown in Fig. 1(d), the microstructure of TR 3 consists of ferrite, bainite and cementite. The absence of the retained austenite was also confirmed by X-ray and neutron diffraction as reported in ref. 21. Therefore, in the present annealing experiments, TR1 and TR2 are predicted to show minor difference and therefore interesting is to compare TR1 or TR2 with TR3.

\subsection{Dilatometry}

The dilatometry curves obtained for TR2 and TR3 are compared in Fig. 2. As seen, both of them are quite similar except at heating around 300 to $400^{\circ} \mathrm{C}$. It is estimated that the decomposition of the retained austenite to ferrite and cementite occurred in TR2 accompanying specimen expansion. Since austenite could not be confirmed in TR3, such a decomposition step did not exist. To be noted is that both of TR2 and TR3 show almost identical reverse transformation temperature, $\mathrm{A}_{\mathrm{cl}}\left(=740^{\circ} \mathrm{C}\right)$. It indicates that the microstructures of the both specimens just before the onset of reverse transformation are similarly composed of ferrite and cementite, resulting in approximately same transformation temperature.

\subsection{In situ EBSD Observations on the Surface during Heating}

Specimen was first heated at a high speed up to around $A_{c 1}$ temperature. As can be observed in Fig. 3(a), i.e., at $751^{\circ} \mathrm{C}$, the volume fraction of austenite looks to become larger, suggesting the onset of austenite reverse transformation. This is in good agreement with the dilatometry result. It is, however, puzzling that the austenite region vanished with further increasing of temperature as is observed in Fig. 3(d) without showing the austenite grain growth. Austenite region was hardly observed with heating for a while. Then, austenite grains appeared by heating up to $924^{\circ} \mathrm{C}$ (see Figs. 4(a), 4(e)), much higher than $A_{c 1}$ in Fig. 2. After that, with increasing temperature, the region of austenite increases as shown in Fig. 4. Some austenite grains with annealing twin labelled A in Figs. 4(b) and 4(f) as an example are found to grow. On the other hand, another grain labelled B in (b) and (f) is found to shrink with further annealing. It is frequently observed that a new grain appeared suddenly from under the surface invading the surrounding grains to become a coarse grain. Finally at $997^{\circ} \mathrm{C}$ in (d) and (h), the surface

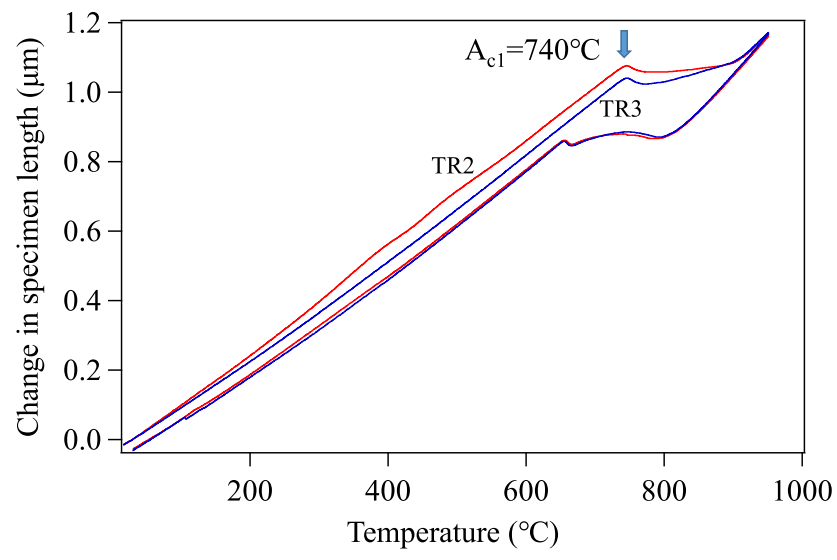

Fig. 2. Dilatometry curves for TR2 and TR3. (Online version in color.) of the specimen was covered almost entirely by austenite grains. Since the austenite grain nucleation is considered to take place not only on the surface but also inside the specimen, it is not enough to monitor the microstructural change on the surface to discuss the nucleation and growth behavior of the austenite reverse transformation. Here, very serious problems of this in situ EBSD observation include that transformation temperatures were about $200^{\circ} \mathrm{C}$ higher than those determined by the conventional dilatometry test. The reason of this discrepancy must be made clear.

Then, the change in chemical composition was measured using rf glow discharge optical emission spectroscopy (rf-GDOES: HORIBA GD-Profiler 2) with serial removal of surface layer. Here, the measurement (discharge) area diameter was $4 \mathrm{~mm}$; rf power, $35 \mathrm{~W}$; argon gas pressure, $600 \mathrm{~Pa}$; sputtering mode, pulse mode; measurement depth, $10 \mu \mathrm{m}$. The obtained results are depicted in Fig. 5, in which (a) and (b) were obtained from a specimen not heated and the specimen after in situ EBSD measurement, respectively. As seen in (b), Mn and C concentrations are lowered in the region from the surface to approximately $3 \mu \mathrm{m}$ in depth. Higher concentrations of $\mathrm{O}, \mathrm{C}, \mathrm{Si}$, and $\mathrm{Mn}$ at the surface were caused by oxidation during specimen preparation and $\mathrm{C}$ contamination. The chemical compositions examined at the surface by EDS analysis have also revealed that $\mathrm{C}$ and Mn contents were lowered after heating for in situ EBSD measurement. Therefore, in addition to decarburizing, Mn atoms must easily be desorbed from the surface in a high vacuum due to its higher equilibrium vapor pressure.

The diffusion length $L$ for Mn was estimated by tracking the heat carrier from $\mathrm{RT}$ to $800^{\circ} \mathrm{C}$ with a heating rate of $3^{\circ} \mathrm{C} / \mathrm{min}$ and the obtained result was approximately $2 \mu \mathrm{m}$ (the details of calculation, see Appendix). This value is comparable with that reported by Tomida and Tanaka. ${ }^{24)}$ They have also claimed that $\mathrm{C}$ atoms would diffuse from the lower
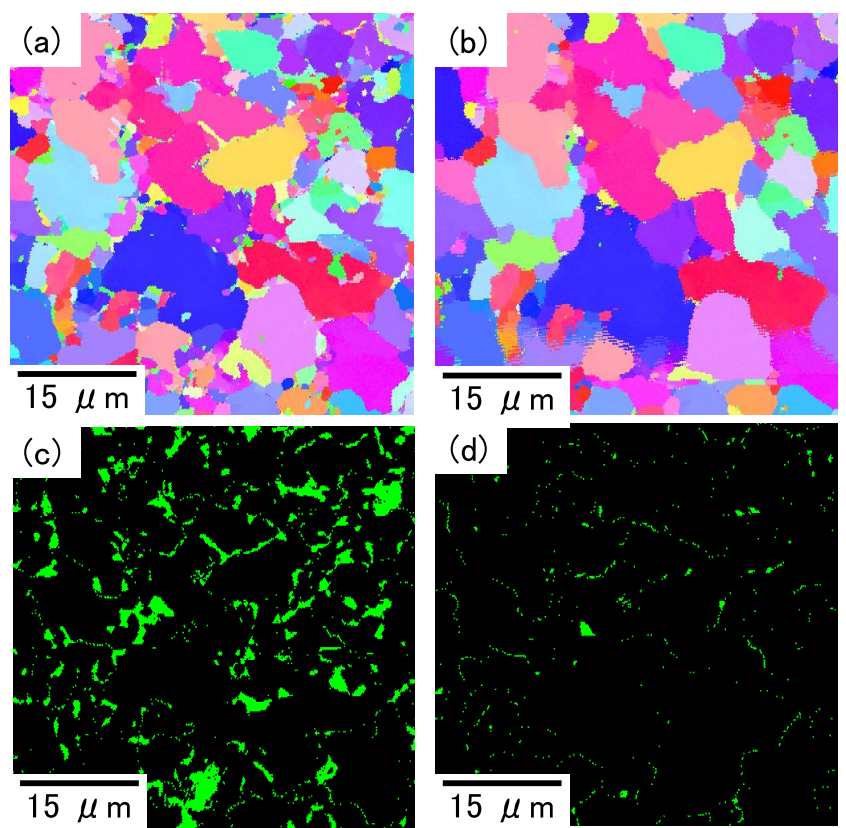

Fig. 3. Disappearance of austenite with heating observed by in situ EBSD measurements for TR2: (a) $751^{\circ} \mathrm{C}$, IPF map, (b) $769^{\circ} \mathrm{C}$, IPF map, (c) $751^{\circ} \mathrm{C}$, phase map (austenite volume fraction: 0.101 ) and (d) $769^{\circ} \mathrm{C}$, phase map (0.014). (Online version in color.) 

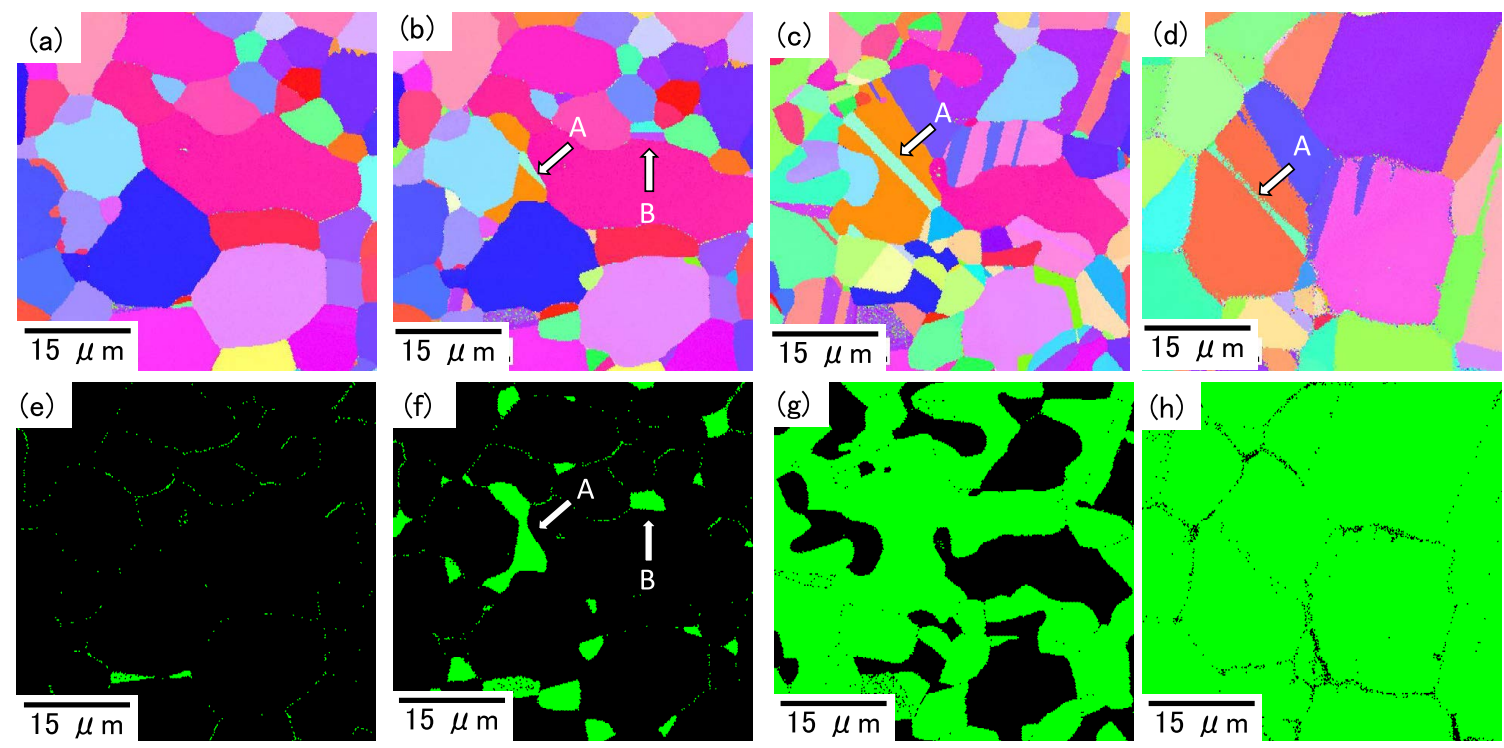

Fig. 4. Austenite reverse transformation behavior observed with EBSD for TR2: (a)-(d) IPF maps, (e)-(h) phase maps, (a), (e) $924^{\circ} \mathrm{C}$ (austenite volume fraction: 0.009), (b), (f) $940^{\circ} \mathrm{C}$ (0.083), (c), (g) $964^{\circ} \mathrm{C}(0.640)$, and (d), (h) $997^{\circ} \mathrm{C}$ (0.982). (Online version in color.)
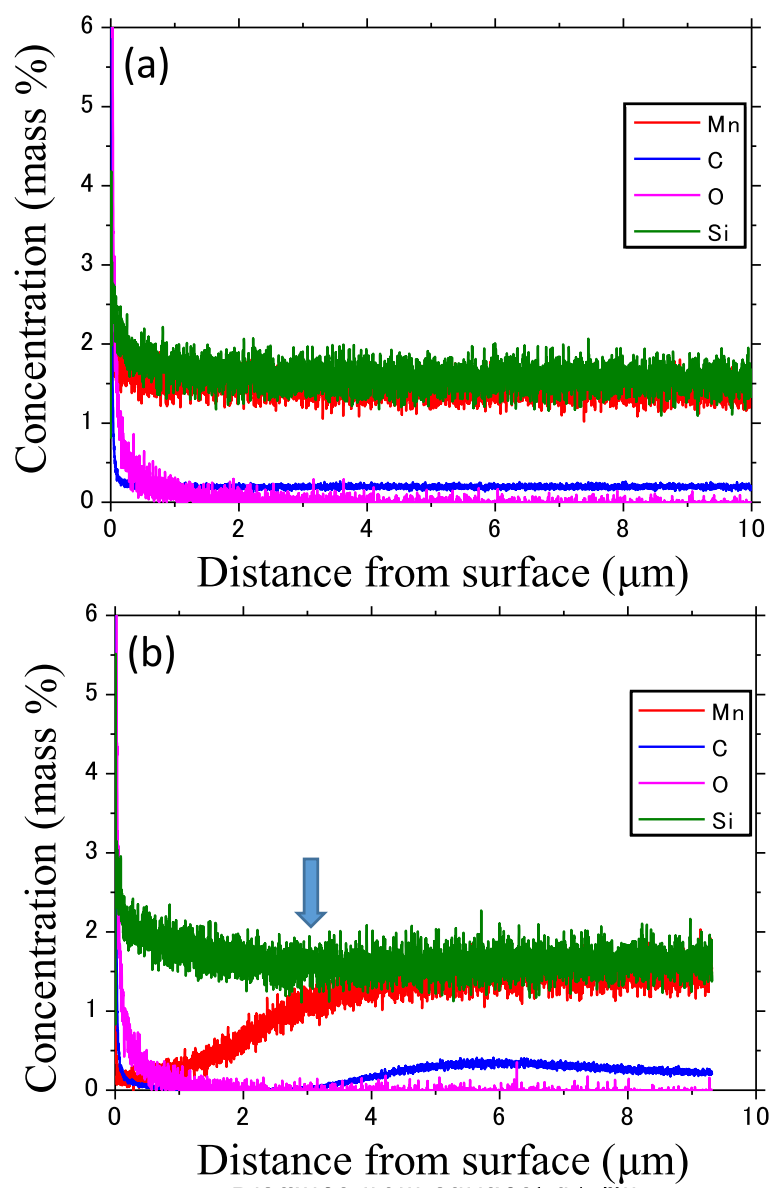

Fig. 5. Chemical compositions as a function of the depth from surface obtained by rf glow discharge optical emission spectroscopy for the EBSD specimens: (a) specimen not heated and (b) the specimen after in situ EBSD measurement. (Online version in color.)

Mn content region (near surface) towards higher region, i.e., the inner side of a specimen, resulting in the decrease of $\mathrm{C}$ concentration near the surface. Taking a close look at Fig. 5, one would recognize a region with slight increase in $\mathrm{C}$ concentration around $5.5 \mu \mathrm{m}$ deep from the surface. This would be corresponding to Tomida and Tanaka's result. ${ }^{24)}$ Another possible reason of carbon enrichment inside the specimen would be attributed to the ferrite transformation on cooling, which preferentially started from the surface. However, as was discussed by Alvarenga et al., ${ }^{25)}$ decarburization from the surface, particularly before the onset of austenite reversion, would seriously take place. If we did similar computation of Appendix for carbon, the diffusion length $L$ for $\mathrm{C}$ is about 100 times larger than that for $\mathrm{Mn}$.

Hence, the observed reverse transformation with in situ EBSD measurements was surface phenomenon, different from that occurred inside the specimen. If $\mathrm{Mn}$ and $\mathrm{C}$ concentrations decreased, i.e., $\mathrm{Fe}-\mathrm{Mn}-\mathrm{Si}-\mathrm{C}$ alloy changed to nearly Fe-Si alloy, ferrite phase would became more stable, resulting in showing a higher reverse transformation temperature as more quantitative discussion will be given in $\$ 3.6$.

\subsection{In situ X-ray Diffraction during Heating}

Figure 6 depicts the changes in 110 ferrite and 111 austenite peaks with heating and cooling in order to observe the decomposition of the retained austenite and austenite reverse transformation behavior, which were not clear by in situ EBSD observation in $\S 3.3$. The austenite 111 diffraction peak was observed at $25^{\circ} \mathrm{C}$ in (a) for TR2 but not in (b) for TR3. More detailed profiles for TR2 obtained at 400, 500, 910 and $950^{\circ} \mathrm{C}$ are presented in Fig. 7.

First, the decomposition of the retained austenite will be discussed. As seen, small peak for 111 austenite is visible below $400^{\circ} \mathrm{C}$, and hardly detected at $500^{\circ} \mathrm{C}$. This must be corresponding to the specimen dilatation behavior observed in Fig. 2, although the temperature region seems slightly higher.

Second, concerning the austenite reverse transformation, the austenite peaks did not appear until temperature increased up to $930^{\circ} \mathrm{C}$, much higher than $\mathrm{A}_{\mathrm{c} 1}\left(740^{\circ} \mathrm{C}\right)$ determined by the dilatometry test. Characteristic features of X-ray diffraction profiles observed in Figs. 7(c) and 7(d) include the appearance of a new peak not related to austenite, ferrite and cementite, and peak splits for ferrite 
and austenite. A new peak observed in Figs. 7(c) and 7(d) is suspected to be oxide like FeO. After the measurement, the color of the surface was changed. The rf-GDOES measurement described above was also carried out and the obtained result was complicated showing serious oxidation, which hindered to reveal the real $\mathrm{Mn}$ and $\mathrm{C}$ concentrations in the steel matrix. It was found oxygen atoms diffused into the specimen deeper than $10 \mu \mathrm{m}$. Hence, more precise experiment is needed to make clear the change in chemical compositions during in situ X-ray diffraction measurement.

Concerning the diffraction peak split observed at higher temperatures in Fig. 7, a possible reason would be the grain growth accompanying an increase of crystal perfectness. This must bring decreasing of line profile broadening leading to the separation of overlapped $\mathrm{K}_{\alpha 1}$ and $\mathrm{K}_{\alpha 2} \mathrm{X}$-ray diffractions.

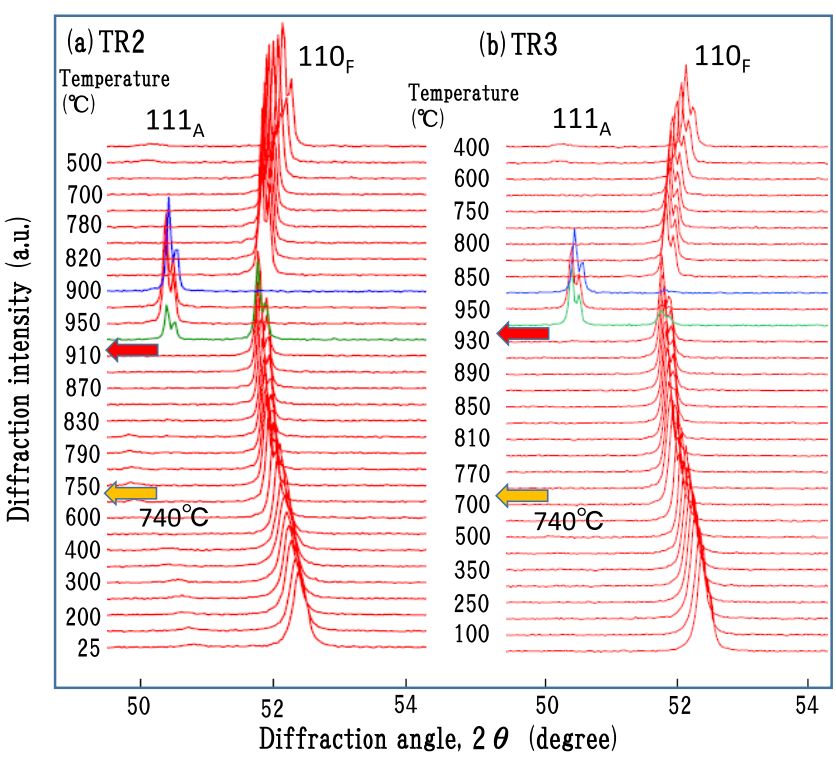

Fig. 6. Changes in austenite 111 and ferrite 110 peaks of X-ray diffraction during heating and cooling: (a) TR2 and (b) TR3. (Online version in color.)

\subsection{Microstructural Evolution Observed by in situ Neutron Diffraction}

The results of in situ neutron diffraction measurements are presented in Figs. 8, 9 and 10. The changes in 111 austenite and 110 ferrite peaks during heating are presented in Fig. 8 , in which the appearance and disappearance of these peaks on heating are well monitored. The diffraction profiles at typical temperatures are depicted in Fig. 9. As seen, austenite exists in TR2 but not in TR3 at RT. The decomposition behavior of the retained austenite is clearly confirmed to occur from 400 to $500^{\circ} \mathrm{C}$ for TR2, showing a good agreement with the X-ray result. In Fig. 10, the austenite volume fraction calculated by the conventional texture correction method was plotted as a function of temperature. Concerning the details of estimation of austenite volume fraction from diffraction profiles, the readers are recommended to refer to Refs. 17-21. As was discussed in details in these reports, the volume fraction calculated from the profiles obtained in the $\mathrm{R}$ direction was higher than that in the $\mathrm{N}$ direction, but the difference was less than $2 \%$, so that only the results in the $\mathrm{R}$ direction were plotted in Fig. 10. Very

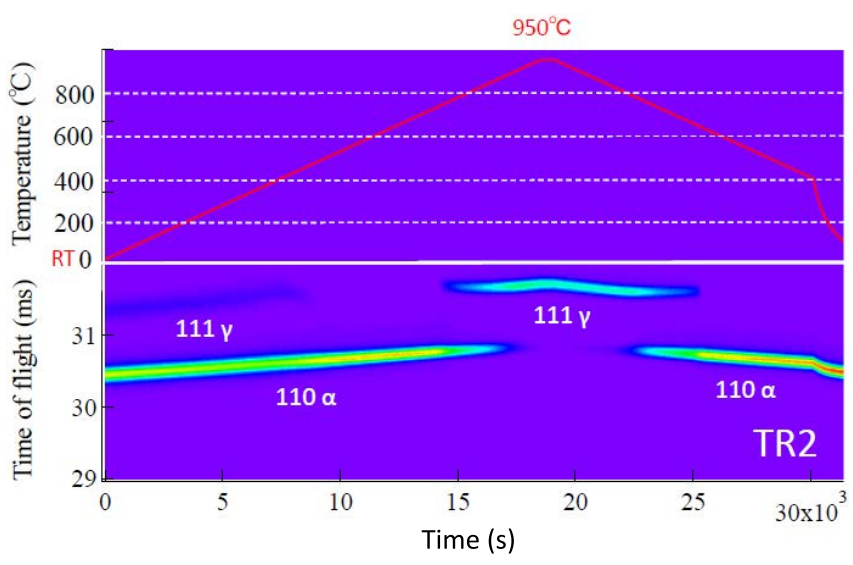

Fig. 8. Changes in neutron diffraction intensities for 111 austenite $(\gamma)$ and 110 ferrite $(\alpha)$ with heating for TR2. (Online version in color.)

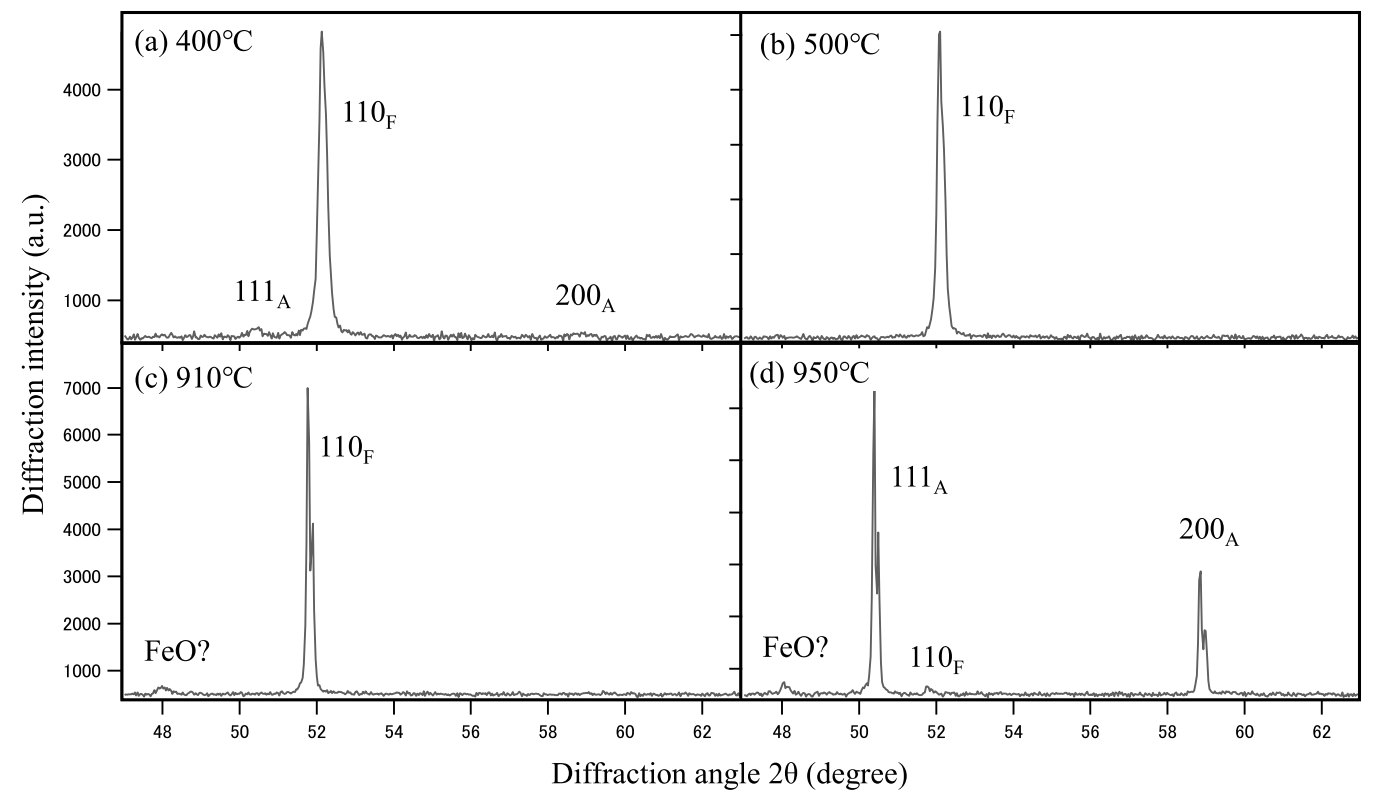

Fig. 7. X-ray diffraction profiles obtained at $400^{\circ} \mathrm{C} \mathrm{(a),} 500^{\circ} \mathrm{C}(\mathrm{b}), 910^{\circ} \mathrm{C}$ (c) and $950^{\circ} \mathrm{C}$ (d) for TR2. 


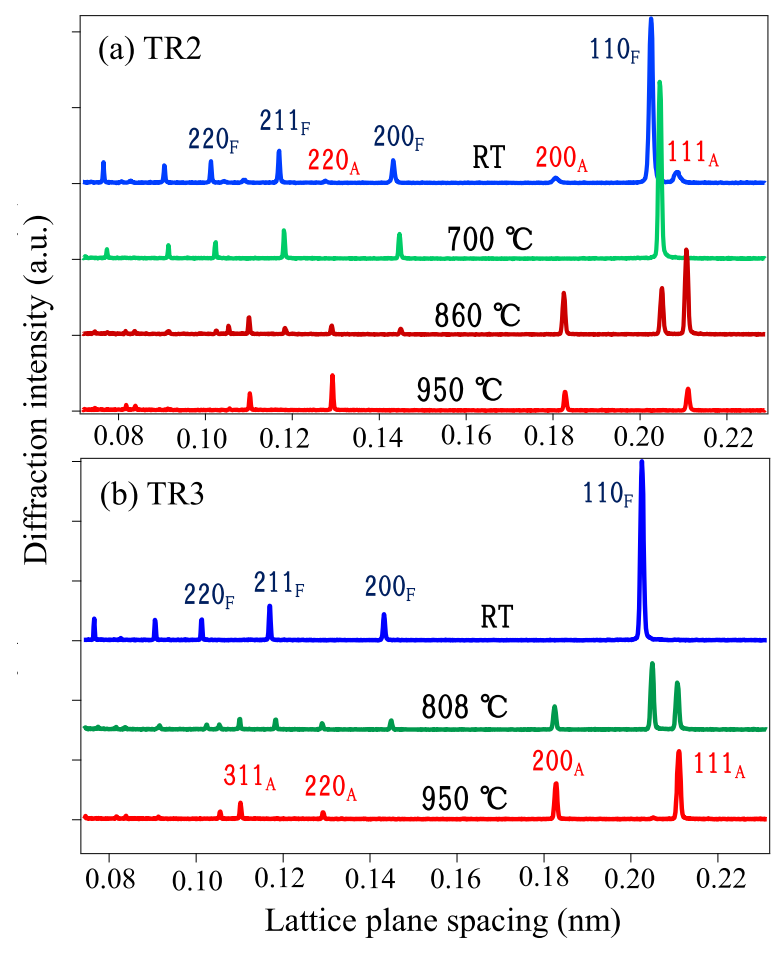

Fig. 9. Neutron diffraction profiles obtained at various temperatures: (a) TR2 and (b) TR3. (Online version in color.)

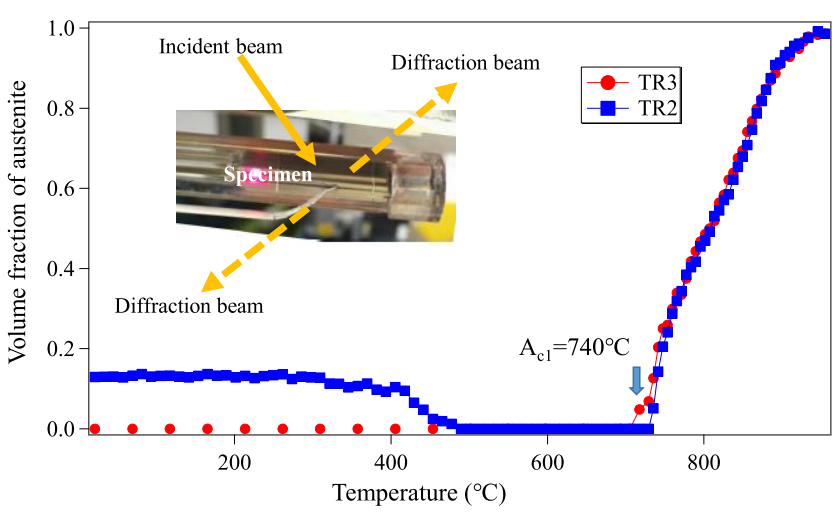

Fig. 10. Volume fractions of austenite determined by neutron diffraction as a function of temperature. (Online version in color.)

important is that the onset of austenite reverse transformation is found near $740^{\circ} \mathrm{C}$, showing a good agreement with the result of dilatometry. This is because neutron diffraction enables us to monitor the bulky averaged information hardly influenced by surface phenomenon.

Different from dilatometry measurement, in situ neutron diffraction measurement provides more fruitful insights on microstructure change. As examples, lattice constants of ferrite and austenite were determined using the Z-Rietveld analysis $^{26)}$ and the obtained results are presented in Fig. 11. It is found in (a) that the austenite lattice constant increases with increasing temperature due to thermal expansion. Around $400^{\circ} \mathrm{C}$, the deviation from thermal expansion line is observed. It is speculated that carbon enrichment occurs with decreasing of austenite volume fraction as is observed in Fig. 10. Most likely mechanism of decomposition of the retained austenite predicted from the present results, would be (1) the increase of $\mathrm{C}$ concentration of austenite with fer-

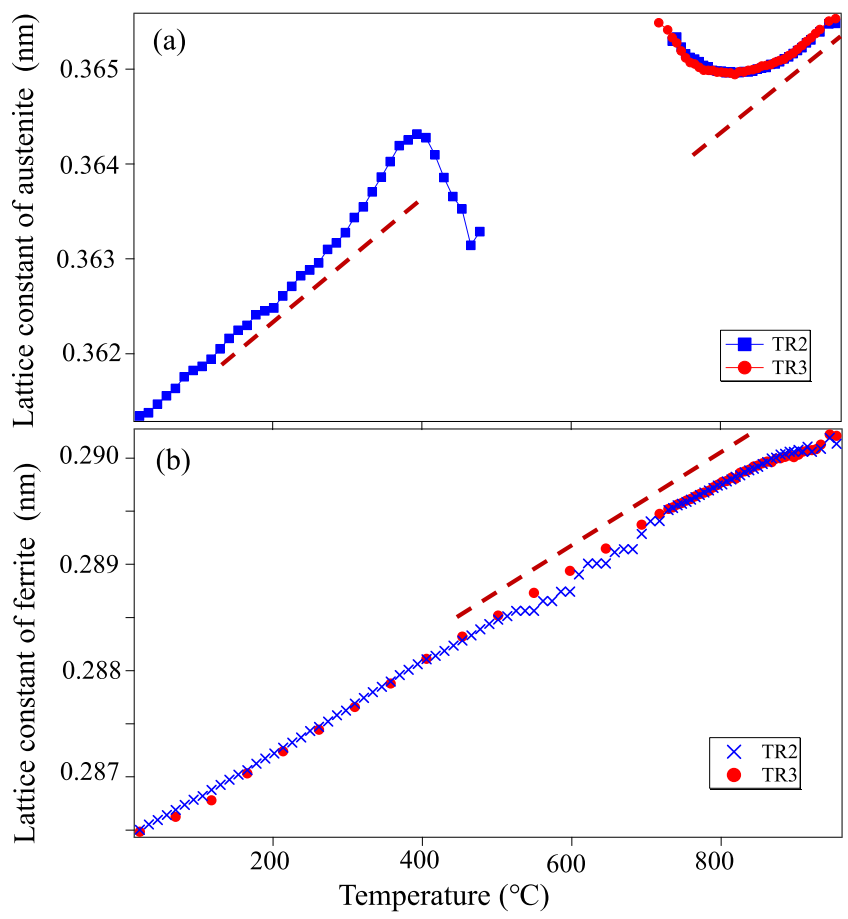

Fig. 11. Changes in the austenite and ferrite lattice constants determined by neutron diffraction with heating for TR2 and TR3. (Online version in color.)

rite formation, followed by the precipitation of cementite accompanying the decrease in austenite volume fraction as well as decrease in $\mathrm{C}$ concentration of austenite. Since there seems to be slight deviation from the thermal expansion line of ferrite in Fig. 11(b), i.e., a little bit of shrinking, it is speculated to be the generation of internal stress distribution with the progress in austenite decomposition; hydrostatic tensile stress generated in austenite phase would enlarge its lattice parameter. The detailed decomposition mechanism on the retained austenite is still open for discussion and the in situ neutron diffraction data must be of use to make clear the underlying mechanism.

Another interesting result found in Fig. 11 is related to the austenite reverse transformation behavior. As is observed in Fig. 10, the result of TR3 is quite similar to that of TR2 at higher temperatures, although the decomposition stage is not found at lower temperatures. Hence, in both of the TR2 and TR3 cases, the microstructure just before the onset of reverse transformation is believed to consist of ferrite and cementite. The nucleation of austenite grain must be ferrite/ cementite interface and therefore the carbon concentration of austenite must be high with dissolving of cementite particles. Hence the austenite lattice constant is found to deviate towards much higher side from the thermal expansion line as observed in Fig. 11(a). With increasing the austenite volume fraction, the austenite lattice constant approaches to its thermal expansion line. Here, the ferrite lattice constant is also found to deviate toward lower values from its thermal expansion line, indicating the generation of hydrostatic compressive internal stress caused by the transformation strains. Therefore, the deviation of austenite lattice constant must include the influence of hydrostatic tensile stresses which are balanced with those in the ferrite phase. 


\subsection{Comparison of the Results Obtained by Four Dif- ferent Methods}

In this investigation, four different techniques were examined to estimate the change in austenite volume fraction upon heating. The obtained results are compared in Fig. 12. As seen, the result of neutron diffraction shows a good agreement with that by dilatometry. However, the results of $\mathrm{X}$-ray and EBSD are much different from those by neutron diffraction and dilatometry. In the latter two techniques, it is inevitable to be influenced by surface, which hinders the understanding of the real phenomenon happening in a bulk specimen.

The information depths corresponding to electron, X-ray and neutron beam are not easy to make clear because many influential factors have to be taken into consideration. According to a recent paper titled "an experimental viewpoint on the information depth of EBSD" by Wisniewski and Russel, ${ }^{27)}$ the depth of the effective information volume of EBSD performed with a voltage of $20 \mathrm{kV}$ is larger than $100 \mathrm{~nm}$ instead of the $40 \mathrm{~nm}$ published in the past. The information depth is dependent on many influential factors but roughly considered to be about a few $100 \mathrm{~nm}$ for steel. On the other hand, quantum beam intensity $I(x)$ decreases with penetration (flight) path length following Eq. (1).

$$
I(x)=I_{0} \exp (-\mu x)
$$

Here, $I_{0}, \mu$ and $x$ refer to the incident beam intensity, linear absorption coefficient and the length of flight path, respectively. If we employ the $\mu$-values of $257 \mathrm{~mm}^{-1}$ for the present X-ray beam and $0.012 \mathrm{~mm}^{-1}$ for neutron, ${ }^{28)}$ the values of $x$ where the intensity ratio of diffraction beam to the incident one to be $1 / e(=1 / 2.7182)$, would be 0.00389 $\mathrm{mm}$ for X-ray and $83 \mathrm{~mm}$ for neutron. In case of the scattering angle, $2 \theta=90$ degrees, the depth from the surface is approximately $1.4 \mu \mathrm{m}$ for X-ray whereas $30 \mathrm{~mm}$ for neutron. Although more detailed consideration is needed to evaluate the influential depths for electron, X-ray, and neutron beams, approximately estimated depths would be $100 \mathrm{~nm}$ for electron, a few $\mu \mathrm{m}$ for X-ray and a few $\mathrm{cm}$ for neutron beam. Hence, it would be concluded that neither EBSD nor X-ray diffraction could trail the transformation behavior in $\mathrm{Mn}$ and/or $\mathrm{C}$ bearing steels at elevated temperatures, because the chemical compositions at the surface layer with approximately $3 \mu \mathrm{m}$ were altered.

The results of calculation using Thermo-Calc TCFE6

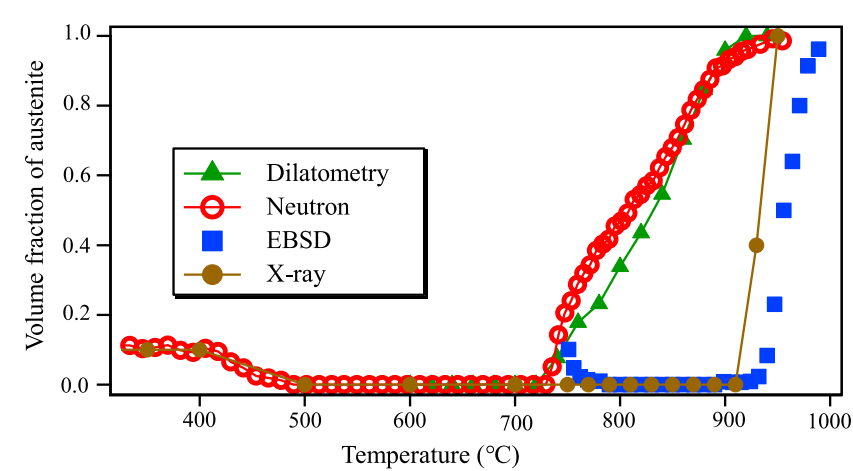

Fig. 12. Changes in austenite volume fraction as a function of temperature determined by the four different methods for TR2. (Online version in color.) have revealed that the austenite transformation start temperatures are $708^{\circ} \mathrm{C}$ for $\mathrm{Fe}-1.5 \mathrm{Mn}-1.52 \mathrm{Si}-0.2 \mathrm{C}$ (inside of specimen), $756^{\circ} \mathrm{C}$ for Fe-1.52Si-0.2C (Mn depletion case), $864^{\circ} \mathrm{C}$ for $\mathrm{Fe}-1.5 \mathrm{Mn}-1.52 \mathrm{Si}$ (C depletion case) and $903^{\circ} \mathrm{C}$ for $\mathrm{Fe}-$ $1.52 \mathrm{Si}$ (both of $\mathrm{Mn}$ and $\mathrm{C}$ depletion case). The measured temperatures were $740^{\circ} \mathrm{C}$ by dilatometry, $924^{\circ} \mathrm{C}$ by EBSD, $910-930^{\circ} \mathrm{C}$ by X-ray and $730-740^{\circ} \mathrm{C}$ by neutron, so that the discrepancy between the highest and lowest temperatures is approximately $200^{\circ} \mathrm{C}$. Hence, the higher transformation temperatures determined by in situ EBSD measurement is believed to be caused by the depletion of both $\mathrm{Mn}$ and C. This is probably similar to the case of in situ X-ray diffraction but the influence of oxidation must be added.

\section{Summary}

The microstructural change upon heating for a $1.5 \mathrm{Mn}-$ $1.5 \mathrm{Si}-0.2 \mathrm{C}$ steel was in situ monitored using dilatometry, electron back scatter diffraction (EBSD), X-ray diffraction and neutron diffraction. The main conclusions obtained would be summarized as follows.

(1) The reversion kinetics showed excellent agreements between dilatometry and neutron diffraction, whereas the austenite formation was observed to start at much higher temperatures in cases of EBSD and X-ray diffraction measurements. Such discrepancy in transformation temperature is attributed to the change in chemical compositions near the surface of a specimen heated to elevated temperatures either in vacuum (EBSD) or in a helium gas atmosphere (X-ray); $\mathrm{Mn}$ and $\mathrm{C}$ concentrations at near surface layer were found to decrease by heating.

(2) In situ neutron diffraction enable us to investigate the changes in lattice constants of ferrite and austenite, showing not only thermal expansion but also suggesting carbon enrichment and phase stresses during the decomposition of the retained austenite and austenite reversion upon heating.

\section{Acknowledgements}

We would like to thank Dr. K. Aizawa of J-PARC center, JAEA and Dr. T. Fukino of TSL Solutions Co. for their helps at neutron diffraction and EBSD measurement, respectively. The in situ neutron diffraction measurements were performed at J-PARC MLF through the project No 2015A0153. This paper is based on the results obtained in a future pioneering project commissioned by the New Energy and Industrial Technology Organization (NEDO). Research discussion and advices given by Dr. M. Ohmura of NIMS, Dr. N. Sano of Nippon Steel and Sumitomo Metal Co., Dr. H. Nakamichi of JFE steel Co., Dr. T. Murakami of Kobe Steel Co. and members of Innovative Structural Materials Association (ISMA) are acknowledged.

\section{REFERENCES}

1) O. Matsumura, Y. Sakuma and H. Takechi: Trans. Steel Inst. Jpn., 27 (1987), 570.

2) Y. Tomota, H. Tokuda, Y. Adachi, M. Wakita, N. Minakawa, A. Moriai and Y. Morii: Acta Mater., 52 (2004), 5737.

3) K. Asoo, Y. Tomota, S. Harjo and Y. Okitsu: ISIJ Int., 51 (2011), 145.

4) P. J. Jacques, Q. Furnemont, F. Lant, T. Pardoen and F. Delannary: Acta Mater., 55 (2007), 3681.

5) J. Speer, D. Matlock, B. De Cooman and J. Schroth: Acta Mater., 51 
(2003), 2611

6) E. J. Seo, L. Cho, Y. Estrin and B. C. De Cooman: Acta Mater., 113 (2016), 124.

7) C. Garcia-Mateo, F. G. Caballero and H. K. D. H. Bhadeshia: ISIJ Int., 43 (2003), 1238.

8) I. B. Timokhima, H. Beladi, X. Y. Xiong, Y. Adachi and P. D. Hodgson: Acta Mater., 59 (2011), 5511.

9) W. Gong, Y. Tomota, Y. Adachi, A. M. Paradowska, J. F. Kelleher and S. Y. Zhang: Acta Mater., 61 (2013), 4142.

10) W. Gong, Y. Tomota, Y. H. Su and S. Harjo: Acta Mater., 85 (2015), 243.

11) H. Natsumeda, A. Kitahara and S. Hashimoto: Tetsu-to-Hagané, 102 (2016), 525.

12) Y. B. Wang, L. Wang and M. X. Huang: Mater. Sci. Eng. A, 674 (2016), 59 .

13) ASTM E975-13: 2003, Standard Practice for X-ray Determination of Retained Austenite in Steel with Near Random Crystallographic Orientation.

14) P. J. Jacques, S. Allain, O. Bouaziz, A. De, A. F. Gourgues, B. M. Hance, Y. Houbasert, J. Huang, A. Iza-Mendia, S. E. Kruger, M. Radu, L. Samek, J. Speer, L. Zhao and S. van der Zwaag: Mater. Sci. Technol., 25 (2009), 567.

15) S. Chen, Y. Tomota, Y. Shiota, Y. Tohmine and T. Kamiyama: Tetsuto-Hagané, 92 (2006), 557.

16) T. Gnäupel-Herold and A. Creuziger: Mater. Sci. Eng. A, 528 (2011), 3594.

17) P. G. Xu, Y. Tomota, Y. Arakaki, S. Harjo and H. Sueyoshi: Mater Charact., 127 (2017), 104.

18) S. He, Y. Tomota, Y. H. Su, W. Gong, S. Harjo and Z. Zhao: ISIJ Int., 55 (2015), 686

19) T. Shinozaki, Y. Tomota, T. Fukino and T. Suzuki: ISIJ Int., 57 (2017), 533.

20) Y. Tomota, W. Gong, S. Harjo and T. Shinozaki: Scr. Mater., 133 (2017), 79

21) Y. Tomota, N. Sekido, P. G. Xu, S. Harjo, M. Tanaka, T. Shinohara, Y. H. Su and A. Taniyama: Tetsu-to-Hagané, 103 (2017), 573.

22) K. Sugimoto, N. Usui, S. Kobayashi and S. Hashimoto: Tetsu-toHagané, 78 (1992), 1480.

23) S. Harjo, T. Ito, K. Aizawa, H. Arima, J. Abe, A. Moriai, T. Iwahashi and T. Kamiyama: Mater. Sci. Forum, 681 (2011), 443.

24) T. Tomida and T. Tanaka: Tetsu-to-Hagané, 79 (1993), 1350

25) H. D. Alvarenga, T. Putte, N. Steenberge, J. Sietsma and H. Terryn: Metall. Mater. Trans. A, 46A (2015), 123.

26) R. Oishi, M. Yonemura, Y. Nishimaki, S. Torii, A. Hoshikawa, T. Ishigaki, T. Morishima, K. Mori and T. Kamiyama: Nucl. Instrum. Methods Phys. Res. A, 600 (2009), 94.

27) W. Wisniwski and C. Russel: Scanning, 38 (2016), 164.

28) G. E. Bacon: Neutron Diffraction, 2nd ed., Oxford University Press, London, (1967), 61.

29) Steel and Alloy Elements, ISIJ, Tokyo, (2015), 566.

\section{Appendix A}

For consideration on a Mn depleted layer that can potentially develop during heating of a plate-shaped specimen, $\mathrm{Mn}$ concentration profile from the surface is numerically calculated hereafter. The calculation is made under the assumptions: (1) Mn sublimation occurs instantaneously at the outmost atomic layer of the surface at all temperatures during heating, (2) the kinetic of Mn sublimation is controlled by diffusivity of $\mathrm{Mn}$ in $\alpha$-Fe, (3) Mn diffusivity is independent of its concentration and given by the impurity diffusion coefficient, and (4) Mn concentration at the surface is always kept constant at zero. Since the Mn diffusion is one dimensional, and the diffusion coefficient is independent of Mn concentrations within the range of homogeneity considered, the Fick's second law can be written as follows:

$$
\frac{\partial C}{\partial t}=D \frac{\partial^{2} C}{\partial x^{2}}
$$

, where $C$ is the Mn concentration, $D$ is the diffusion coefficient, $t$ is time, and $x$ is the distance from the surface. The continuum of Eq. (A1) can be transformed into the finite difference expression.

$$
\mathrm{C}_{x}^{t+\Delta t}=\mathrm{C}_{x}^{t}+D \frac{\Delta t}{\Delta x^{2}}\left(\mathrm{C}_{x+\Delta x}^{t}-2 \mathrm{C}_{x}^{t}+\mathrm{C}_{x-\Delta x}^{t}\right) \ldots \ldots
$$

Here $\mathrm{C}_{x}^{t}$ is the Mn concentration at distance $x$ and time $t$. Since considered here is the Mn diffusion during heating at a constant heating rate, the diffusion coefficient $D$ in Eq. (A2) is a time-dependent variable. The diffusion coefficient of Mn at $t=i \Delta \mathrm{t}$, expressed as $D^{\mathrm{i}}$, is given by:

$$
D^{i}=D_{0} \exp \left(-\frac{Q}{R\left(T_{s}+i v \Delta t\right)}\right)
$$

, where $Q$ is the activation energy for diffusion, $D_{0}$ is the pre-exponential factor, $R$ is the gas constant, $T_{\mathrm{s}}$ is the starttemperature of heating, and $v$ is the heating rate. Therefore the Mn concentration at $x=j \Delta x$ and $t=i \Delta \mathrm{t}$ can be formulated by the following equation.

$$
\mathrm{C}_{j}^{i+1}=\mathrm{C}_{j}^{i}+\left(\mathrm{C}_{j+1}^{i}-2 \mathrm{C}_{j}^{i}+\mathrm{C}_{j-1}^{i}\right) \frac{\Delta t}{\Delta x^{2}} D_{0} \exp \left(-\frac{Q}{R\left(T_{s}+i v \Delta t\right)}\right)
$$

Figure A1 shows the numerically analyzed concentration profiles that develop during heating from $20^{\circ} \mathrm{C}$ to (i) $700^{\circ} \mathrm{C}$, (ii) $800^{\circ} \mathrm{C}$, and (iii) $900^{\circ} \mathrm{C}$ at the heating rate of $0.05^{\circ} \mathrm{C} / \mathrm{s}$. The calculation was done with the segment size of $\Delta x=50(\mathrm{~nm})$ and $\Delta t=0.1(\mathrm{~s})$. The impurity diffusion coefficient of $\mathrm{Mn}$ in $\alpha$-Fe used here is given in literature as $\mathrm{D}_{0}=1.5 \times 10^{-4}\left(\mathrm{~m}^{-2}\right)$, and $\mathrm{Q}=234(\mathrm{~kJ} / \mathrm{mol}){ }^{29)}$ Note that, although the above diffusion coefficient is validated in the temperature range from 700 to $760^{\circ} \mathrm{C}$, the numerical analysis was done by using extrapolated values at temperatures below and above this temperature range.
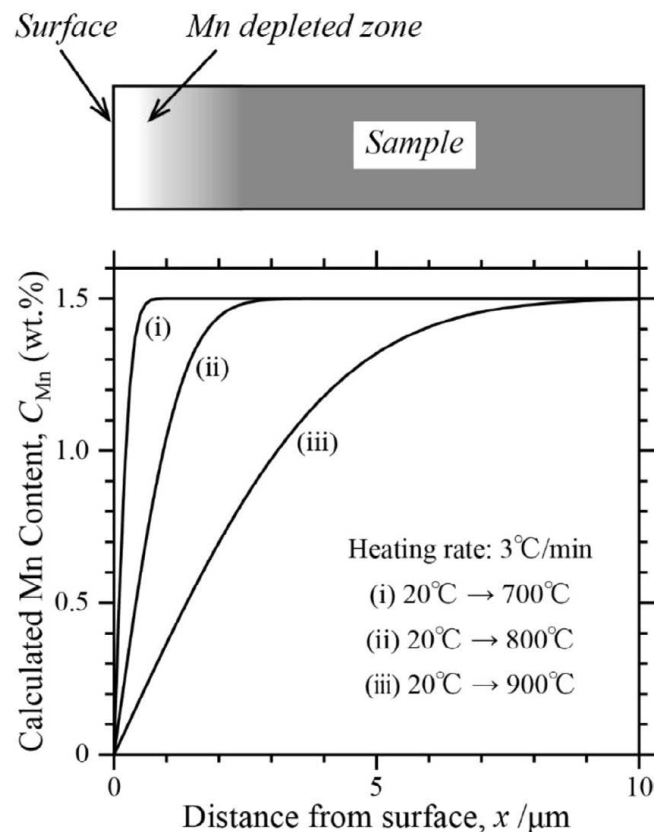

Fig. A1. Computed results of Mn concentration as a function of the depth from the specimen surface. 